\title{
Un estudio diacrónico de ponerse a + INFINITIVO: de la causatividad a la incoatividad
}

\author{
Daniel Cuní Díez ${ }^{1}$ \\ Universitat de Barcelona, España
}

\begin{abstract}
Resumen
El objetivo de este trabajo es el estudio diacrónico de la perífrasis verbal incoativa ponerse $a+$ INF. Para ello, se ha recurrido a un corpus multimodal compuesto por distintas tipologías textuales y que abarca un amplio periodo histórico, desde el siglo XII hasta el siglo XXI. El presente estudio, siguiendo el modelo teórico de Gramática de Construcciones Diacrónica, aboga por una aproximación a las perífrasis verbales basada en el uso. La parte central del trabajo se divide en dos ejes principales: una caracterización semántica y sintáctica de ponerse $a+$ INF y un análisis diacrónico de esta perífrasis verbal.
\end{abstract}

Palabras clave: perífrasis verbal, gramaticalización, Gramática de Construcciones, lingüística histórica.

1 Para correspondencia, dirigirse a: dcunidiez@ub.edu. Departamento de Filología Hispánica, Teoría de la Literatura y Comunicación. Facultad de Filología de la Universitat de Barcelona, Gran Via de les Corts Catalanes, 585, 08007 Barcelona. Tel. +34 (93) 4029052 


\title{
A DIACHRONIC STUDY OF PONERSE A + INFINITIVO: FROM CAUSATIVITY
} TO INCHOATIVITY

\begin{abstract}
The aim of this work is a diachronic study of the inchoative periphrasis ponerse $a+$ INF. To this end, we have used a multimodal corpus which is composed of different textual typologies from the 12 th up to the 21 st century. Drawing on the Diachronic Construction Grammar theoretical model, this study argues for a usage-based approach for the verbal periphrasis studies. The central part of this study has two axes: firstly, a characterisation of ponerse $a+\mathrm{INF}$, and secondly, a diachronic analysis of this verbal periphrasis.
\end{abstract}

Keywords: Verbal periphrasis, grammaticalization, Construction Grammar, historical linguistics.

Recibido: 02/06/19 Aceptado: 07/08/19

\section{INTRODUCCIÓN²}

El principal objetivo del presente trabajo es el estudio diacrónico de ponerse $a+$ INF. Esta perífrasis aspectual expresa sentidos incoativos, esto es, señala el comienzo del evento denotado por el infinitivo. Así, en (1) se indica el inicio de la acción de cantar.

(1) Después los tres juntos se habían puesto a cantar el Barbero, la escena del piano. (Leopoldo Alas “Clarín”, La Regenta, 1884, GradiA)

Para llevar a cabo este objetivo principal, vamos a realizar un análisis diacrónico cuya finalidad es conocer cómo surge esta perífrasis verbal, qué trayectoria evolutiva sigue a lo largo del tiempo, qué clases verbales aparecen en la posición de verbo auxiliado en cada una de sus etapas evolutivas, y

2 Quiero expresar mi agradecimiento al proyecto GRADIA, en especial a la doctora Mar Garachana Camarero, por la oportunidad de poder participar en este monográfico. También quiero dar las gracias a todos los colaboradores de este monográfico por sus sugerencias y observaciones, que han resultado de gran utilidad para la mejora de este capítulo. 
qué características semánticas y sintácticas presenta en sus distintos estadios evolutivos.

El análisis diacrónico mencionado se ha pautado a partir de los parámetros empleados para el estudio de los cambios lingüísticos: la frecuencia de empleo de la construcción, las tradiciones discursivas en las que se documenta, el tipo de sujeto de la construcción, las personas gramaticales y los tiempos verbales en los que se conjuga el auxiliado, y las clases verbales que aparecen en la posición de verbo auxiliado.

Este artículo se organiza en diversos apartados: el APARTADO 2 consiste en la presentación del corpus empleado y de la metodología que se ha seguido para llevar a cabo el análisis. En el APARTADO 3, se va a realizar una caracterización semántica y sintáctica de ponerse $a+$ INF, en la que se van a desarrollar aspectos relevantes para el estudio diacrónico, como los contextos de uso en los que se emplea, los valores semánticos que expresa, las particularidades sintácticas que presenta, la nómina de verbos con los que se combina o las restricciones combinatorias que presenta. Asimismo, se va a incluir una breve discusión sobre la prototipicidad de ponerse $a+$ INF.

Por su parte, el APARTADO 4 muestra el análisis diacrónico, cuantitativo y cualitativo, de la perífrasis estudiada; el APARTADO 5 recoge las ideas principales del trabajo y expone las conclusiones a las que ha llegado tras el análisis y, finalmente, el APARTADO 6 incluye un listado con la bibliografía consultada.

\section{EL CORPUS}

El estudio diacrónico que hemos desarrollado en el presente artículo se fundamenta en el uso. Para ello, hemos realizado un análisis de la perífrasis ponerse $a+$ INF en el corpus multimodal GRADIA, compilado por el grupo de investigación Gramática y Diacronía, de la Universitat de Barcelona.

Hemos elegido este corpus porque está compuesto exclusivamente por ediciones textuales que cumplen los requisitos establecidos por FernándezOrdóñez (2006) y Rodríguez Molina (2010), quienes abogan por recurrir únicamente a testimonios originales o copias cercanas al original.

Además, este corpus reúne un conjunto de fuentes documentales que van del siglo XII al XXI y que comprenden tipologías textuales muy diversas (textos legales, textos historiográficos, textos notariales y administrativos, textos técnicos, textos narrativos, textos ensayísticos, textos epistolares, prensa 
escrita, discursos políticos, literatura sapiencial, diálogos renacentistas, textos orales y teatro). Al contemplar una tipología textual variada, se minimiza la posibilidad de que un cambio quede eclipsado o realzado por el hecho de que una construcción fuese especialmente productiva en una tradición discursiva.

Del corpus GRADIA, se han obtenido 198 ocurrencias. Dado que no se trata de un número muy elevado de casos, se ha recurrido a otros cuerpos de textos para comprobar si se mantienen las tendencias observadas en el corpus principal. En este punto, cabe aclarar que el análisis cuantitativo que se va a desarrollar se basa exclusivamente en los datos obtenidos del corpus GRADIA; de los otros corpus solamente se han tomado ejemplos para apoyar las hipótesis formuladas a partir de los datos del corpus principal.

Para la comparación diacrónica, se ha elegido el Corpus Diacrónico del Español (CORDE), puesto que abarca un amplio periodo de tiempo, desde los inicios del idioma hasta finales del siglo xx. Para el empleo de este corpus, se han cotejado las ediciones de los documentos de donde se han extraído los ejemplos con el trabajo de Rodríguez Molina y Octavio de Toledo (2017), consistente en una exhaustiva relación acerca de la fiabilidad ecdótica de las fuentes incluidas en el corpus académico. Dado que el CORDE no contiene documentos de las últimas décadas, hemos consultado el Corpus del Español del Siglo XXI (CORPES XXI) para cubrir el periodo contemporáneo. Finalmente, para rastrear los antecedentes latinos de la construcción, hemos empleado el Cross Database Searchtool (CDL).

\section{CARACTERIZACIÓN DE PONERSE A + INF}

Ponerse $a+$ inf es una perífrasis verbal de fase. Por lo tanto, se caracteriza por "parcelar el estado de cosas designado por el infinitivo y sus complementos, focalizando un punto o un estadio de la evolución temporal de este" (Rae y Asale 2009: 2168). En concreto, se trata de una perífrasis incoativa, por lo que focaliza el inicio del evento expresado por el infinitivo. Así, en (2), se muestra la acción de llover en su fase inicial.

(2) Por ejemplo, el otro día estábamos en la playa y se puso a llover. (Ricardo Wurgaft, Sanhattan. Confidencias de un lagarto en los 90, 2012, CORPES XXI) 
Como señalan Comer y Enghels (2018a), el inventario de perífrasis verbales incoativas del español es muy amplio, ya que, para expresar el inicio de un determinado evento, los hablantes disponen de distintas construcciones. Aparte de la perífrasis estudiada, pueden recurrir a verbos ingresivos (empezó a llover, comenzó a llover), a verbos de cambio de estado (rompió a llorar) o a verbos de movimiento (se echó a reír), como las opciones más destacadas. De todos modos, "cuanto ganan estas perífrasis en variabilidad del verbo conjugado lo pierden en rentabilidad funcional. En efecto, cada uno de estos auxiliares, en la medida en que tengan un uso mínimamente estable, posee una productividad léxica limitada y en cierta forma complementaria con la de los demás" (Fernández de Castro 1999: 55). Por lo tanto, existen auxiliares menos especializados y que, por lo tanto, presentan una mayor frecuencia de uso, como empezar y comenzar, los cuales no presentan tantas restricciones combinatorias, como veremos a continuación.

\subsection{RASGOS SEMÁNTICOS Y SINTÁCTICOS DE PONERSE A + INF}

García Fernández (2006: 221) afirma que, cuando esta perífrasis selecciona sujetos animados y humanos, expresa que existe cierto esfuerzo, volición o decisión por parte del sujeto en el comienzo del evento. Este sentido añadido implica que el sujeto de la perífrasis solamente puede entenderse como el agente de la acción. Por ejemplo, el enunciado (3) resulta agramatical porque enfermar es un verbo cuyo sujeto experimenta, de manera involuntaria, un cambio de estado, de manera que es incompatible con la restricción de la perífrasis ponerse $a+\mathrm{INF}$ de seleccionar sujetos agentivos. Por el contrario, este enunciado resulta posible con la perífrasis empezar $a+\mathrm{INF}$, la cual no presenta esta restricción combinatoria, como puede observarse en (4).

(3) *Cuando apenas empezó a saborear las delicias de la carne, el marido se puso a enfermar.

(4) Cuando apenas empezó a saborear las delicias de la carne, el marido empezó a enfermar. (Rubén Acosta-Gallagher, Mi primer Olimpo, 2008, CORPES XXI)

Olbertz (1998) sostiene que esta restricción que presenta ponerse $a+$ INF la ha heredado del significado de poner como verbo pleno. Cuando no funciona como auxiliar, poner es un verbo ditransitivo de carácter físico, que expresa el movimiento espacial de un objeto y subcategoriza sujetos agentivos (5). Esta característica se mantiene en los ejemplos de la perífrasis documentados hasta el siglo XVIII. Sin embargo, a medida que avanza el 
proceso de gramaticalización de la perífrasis, esta se va alejando de los valores que presenta el verbo auxiliar en sus usos no perifrásticos, de modo que se pierden también las restricciones heredadas de los usos léxicos del verbo poner. Esto explicaría la progresiva pérdida del control de la acción por parte del sujeto que experimenta la perífrasis en sus últimos estadios evolutivos (vid. APARTADO 4.3.5.).

(5) La tal Irene le puso los cubiertos y dejó ante él una fuente de ensalada tan grande como la mía. (Pedro Zarraluki, Todo eso que tanto nos gusta, 2008, CORPES XXI)

Otra característica de esta perífrasis es su marcado carácter puntual, puesto que "expresa el inicio de una actividad en un momento preciso, generalmente sin transición ni progresión" (RAE y AsAle 2009: 2174). Por esa razón, resulta incompatible que se construya con verbos que expresan una acción gradual, como en el ejemplo (6). En cambio, con otras perífrasis incoativas, como empezar a + INF, no existe dicha restricción, como puede observarse en (7).

(6) *Cuando se puso a amanecer vi un puente rojo, la carretera arbolada.

(7) Cuando empezó a amanecer vi un puente rojo, la carretera arbolada. (Miguel Motta, Los días del agua, 2003, CORPES XXI)

Respecto a la Aktionsart de los verbos auxiliados, cabe señalar que ponerse $a+$ INF no puede construirse con predicados estativos. Esta restricción está motivada por dos razones. La primera es que "la brusquedad o el carácter repentino son propiedades dinámicas que no pueden predicarse del comienzo de situaciones homogéneas o no dinámicas como son las denotadas por los estados" (García Fernández 2006: 222). Así, con ponerse a + INF resulta incompatible un enunciado como (8) porque se trata de un estado; por el contrario, con la perífrasis empezar a + INF sí funciona, puesto que no aporta estos valores de brusquedad (9).

(8) *También se puso a ser consciente de que el petróleo es un recurso finito.

(9) También empezó a ser consciente de que el petróleo es un recurso finito. (Juan Julián Merelo, Las guerras del petróleo, 2015, CORPES $\mathrm{xXI})$

La segunda razón es que el matiz de volición expresado por ponerse $a+$ INF obliga a que el sujeto ejerza el control de la acción denotada por el infinitivo. Esto resulta incompatible con los predicados estativos, puesto que estos no seleccionan sujetos agentivos. Así, mientras en (10) la acción de tener miedo no es compatible con ponerse $a+$ INF porque el sujeto no puede ejercer el 
control de la acción, el enunciado (11) resulta gramatical porque la perífrasis empezar $a+$ INF no aporta ese matiz de volición.

(10) *Entonces volvió a mirar a Sara, y ella se puso a tener miedo de verdad.

(11) Entonces volvió a mirar a Sara, y ella empezó a tener miedo de verdad. (Almudena Grandes, Los aires dificiles, 2002, CORPES XXI)

Por consiguiente, dadas las características que presenta ponerse $a+\mathrm{INF}$, podemos afirmar que se trata de una perífrasis verbal que se construye con predicados dinámicos y durativos, ya que se presupone que la acción que expresa el complejo perifrástico tiene que proseguir, no puede concluir en el mismo momento en el que se inicia. Por lo tanto, resulta imposible que se combine con auxiliados como el de (12).

*Me puse a llegar al trabajo.

Otra restricción que presenta la perífrasis verbal es su limitado contexto de uso, esto es, se trata de un tipo de construcción que se emplea únicamente en ámbitos de proximidad comunicativa, a diferencia de las perífrasis empezar $a++$ INF y comenzar $a+$ INF, las cuales tiene cabida en cualquier registro, como veremos en el APARTADO 4.4.

\subsection{El CARÁCTER PERIFRÁSTICO DE PONERSE A + INF}

A pesar de las restricciones mencionadas, la tradición bibliográfica acepta el carácter perifrástico de ponerse a + INF (Roca Pons 1958; Gómez Torrego 1988, 1999; Fernández de Castro 1990, 1999; Morera 1991; Yllera 1999; Fogsgaard 2002; García Fernández 2006; Rae y Asale 2009).

A propósito de ello, cabe mencionar que, en este artículo, no vamos a entender las perífrasis verbales como una categoría cerrada de la que solo pueden formar parte las construcciones que cumplan unos criterios concretos, puesto que, en la tradición gramatical, cada autor que se ha dedicado al estudio de las perífrasis verbales ha optado por el empleo de unas pruebas específicas, de manera que se han obtenido nóminas de perífrasis muy distintas. En consecuencia, no existe unanimidad respecto a las construcciones que forman parte de la categoría de las perífrasis verbales. Para solventar esta situación, en este trabajo, siguiendo a Garachana (2017), vamos a aplicar la teoría de prototipos al estudio de las perífrasis verbales, de manera que vamos a concebirlas como una categoría radial en la que existen unos miembros más prototípicos, situados en el centro de la categoría, que son aquellos que 
cumplen la mayor parte de los criterios aportados por la gramática tradicional, y otros miembros con un menor grado de perifrasticidad, situados en la periferia, puesto que son aquellos que incumplen varios de los criterios o bien que presentan algunas restricciones semánticas o sintácticas. De esta manera, se solventa la situación mencionada, ya que se permite la inclusión en dicha categoría de construcciones que muestran características propias de las perífrasis verbales, pero que no superan todos los criterios aportados por la gramática tradicional.

En el caso de ponerse $a+\mathrm{INF}$, vamos a asumir que se trata de una perífrasis verbal porque cumple positivamente la mayoría de los criterios; sin embargo, las pruebas no superadas nos conducen a la conclusión de que no se trata de una construcción prototípica, sino marginal, esto es, situada en los límites de la categoría.

\section{ESTUDIO DIACRÓNICO DE PONERSE A + INF}

En este apartado, vamos a mostrar la trayectoria evolutiva que ha seguido la construcción ponerse a + INF, desde los orígenes de la perífrasis incoativa hasta los ejemplos donde se percibe la consolidación del proceso de gramaticalización. Para ello, vamos a tener en cuenta la frecuencia de empleo de la perífrasis, las tradiciones discursivas en las que se documenta, y los cambios semánticos y sintácticos que experimenta a lo largo del tiempo.

\subsection{Frecuencia De EMPLEO POR SigLo}

Las primeras manifestaciones en español de la perífrasis ponerse $a+$ INF se remontan al siglo Xv, como puede observarse en la Tabla 1, donde se recogen los empleos perifrásticos de la construcción a lo largo de la historia del español. Sin embargo, solo alcanza una frecuencia de uso remarcable a partir del siglo XIX, el cual fue un momento decisivo para la cristalización del sistema perifrástico del español (vid. Garachana 2017). 


\begin{tabular}{|c|c|c|c|}
\hline Siglo & Frecuencia absoluta & $\begin{array}{c}\text { Total de palabras } \\
\text { del corpus }\end{array}$ & $\begin{array}{c}\text { Frecuencia por } \\
\text { millón de palabras }\end{array}$ \\
\hline XIII & 0 & 2745347 & 0 \\
\hline XIV & 0 & 1653131 & 0 \\
\hline XV & 2 & 1466863 & 1,36 \\
\hline XVI & 16 & 3603987 & 4,44 \\
\hline XVII & 1 & 2108281 & 0,47 \\
\hline XVIII & 12 & 1309491 & 9,16 \\
\hline XIX & 75 & 1916754 & 39,13 \\
\hline XX & 92 & 2542573 & 36,18 \\
\hline Total & 198 & 17346427 & 11,41 \\
\hline
\end{tabular}

Tabla 1. Frecuencia de empleo de ponerse $a+$ INF por siglo

Como puede observarse en la Tabla 1, en los siglos XIII y XIV no constan ejemplos perifrásticos de ponerse $a+$ INF. El primer ejemplo perifrástico no se documenta hasta el siglo Xv, aunque la frecuencia de empleo en ese siglo $(1,36)$ es muy baja. Comienza a ser un poco más destacable en el siglo XVI, cuando alcanza su frecuencia de aparición más alta hasta el momento $(4,44)$. No obstante, esta vuelve a decaer en el siglo XVII, cuando la frecuencia no llega a un ejemplo por millón de palabras $(0,47)$. En el siglo XVIII se da un repunte en el uso $(9,16)$, pues se dobla la frecuencia del siglo Xvi. De todos modos, sigue tratándose de un empleo residual.

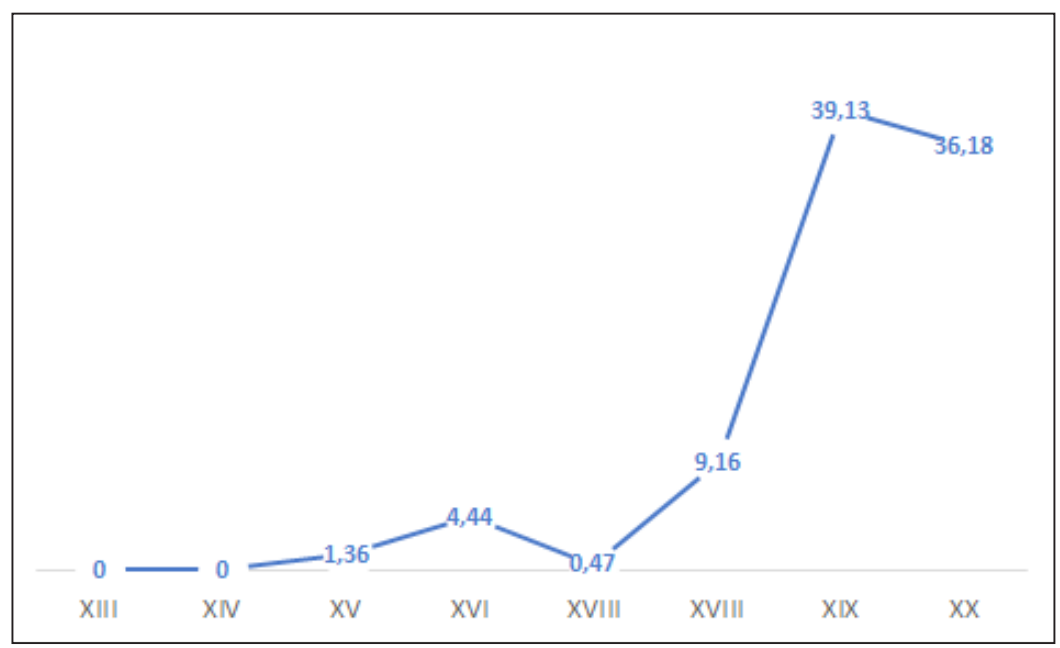

Gráfico 1. Evolución de la frecuencia de empleo de ponerse $a+$ INF por siglo 
A partir del siglo XIX, el empleo de ponerse $a+$ INF empieza a extenderse y la frecuencia de empleo comienza a alcanzar cifras considerables $(39,13)$. Esta se mantiene estable hasta el siglo xx $(36,18)$. Por lo tanto, puede concluirse que se trata de una de las construcciones que afloran en el primer español moderno (vid. Garachana 2017). En efecto, pese a que la frecuencia de empleo de la construcción en el corpus no es muy elevada $(11,41)$, se trata de una construcción que ha experimentado un crecimiento considerable. Esta evolución, sobre la cual se profundizará en el APARTADO 4.2., puede observarse en el Gráfico 1. Nuestra hipótesis es que este aumento en la frecuencia de uso se deba a la especialización de esta perífrasis en contextos de inmediatez comunicativa (vid. APARTADO 4.4.).

\subsection{TRAYECTORIA EVOLUTIVA DE LA PERÍFrasis}

Para conocer los orígenes de la construcción perifrástica, hemos rastreado los usos léxicos que presentaba el poner en los siglos previos a los ejemplos causativos y perifrásticos. Se trata de un verbo que subcategoriza un sujeto agente, un objeto directo y un complemento locativo, como puede observarse en el enunciado (13). Este es el empleo que presenta el verbo poner en la actualidad.

(13) Et porque esta carta sea roborada et confirmada, nos, jurados et alcaldes et todo el conceio de Miranda, mandamos poner en ella nuestro sello. (Anónimo, Carta de donación, 1236, CORDE)

\subsubsection{Las estructuras causativas}

A partir del siglo XIV, se documentan ejemplos donde el verbo poner se sigue combinando con un complemento locativo, pero también selecciona un complemento preposicional formado por la preposición $a$ y por un infinitivo. En este tipo de ejemplos, que vamos a denominar causativos, la construcción no presenta todavía el significado incoativo, pero podría tratarse del punto de partida de la construcción perifrástica. Se trata de estructuras en las que el verbo poner mantiene su significado en tanto que verbo pleno; sin embargo, la construcción al completo permite inferir un sentido incoativo. Así, en el ejemplo (14) poner mantiene su significación locativa, pero la construcción póngalo a cocer en el horno no solo indica que un alimento tiene que colocarse en el horno para que cueza, sino que puede inferirse que, al poner ese alimento en el horno, la acción de cocer va a comenzar. 
(14) Y ponganlo a cozer en el horno y quando fuere bien cocho pongan la mesa para comer. (Anónimo, Sevillana medicina de Juan de Aviñón, 1381-1418, CORDE)

La evolución desde el sentido causativo hasta el incoativo es el resultado de un proceso de naturaleza metonímica por el cual el significado inferido acaba convertido en el valor prototípico de la perífrasis. Como se ha indicado, la estructura causativa permite inferir el sentido incoativo: si el agente coloca algo en un lugar para provocar un efecto, la acción de poner se puede interpretar como el punto de partida para que se dé la acción expresada por el infinitivo. Así, poner el caldo a cocer puede interpretarse tanto en el sentido de que se coloca un cazo de caldo en el fuego para que cueza como en una acepción incoativa, esto es, que la acción de cocer se inicia en el momento en el que se coloca el cazo en el fuego.

Por consiguiente, en este punto, parece que se esté fraguando un cambio semántico que tiene como resultado una nueva significación. Se trata de un cambio que afecta a la semántica de la construcción al completo. Siguiendo a Barðdal y Gildea (2015), en este cambio semántico ponerse $a+$ INF experimenta una evolución desde una SEM1 ('colocar algo en alguna parte') a una SEM2 (significación incoativa). Por el momento, se ha producido, en términos de Traugott y Trousdale (2013), un cambio construccional, ya que atañe solamente a uno de los dos polos de la construcción, en este caso, la semántica.

En latín ya existen ejemplos (15) en los que la construcción puede entenderse tanto como causativa (alguien se coloca en la cama para dormir) como incoativa (alguien comienza a dormir en la cama). Además, el pronombre se ya se encuentra en los ejemplos latinos, de modo que podría ser una herencia de dicha lengua; por lo tanto, su presencia en la perífrasis verbal tendría que explicarse desde el latín. Dado que la construcción española comparte muchos rasgos con la latina, podría pensarse que esta construcción ha llegado al español como un calco del latín. De todos modos, hay que tener en cuenta que, en los ejemplos latinos, poner se combina solamente con verbos locativos, como sentarse (16) o con predicados que presentan un complemento de lugar (15). Esto nos conduce a pensar que se trata de una construcción todavía cercana a la etimológica y que es en español cuando evoluciona hacia la perífrasis incoativa actual. Por esa razón, en este trabajo vamos a considerar que la emergencia de la perífrasis ponerse $a+$ INF responde a la confluencia de dos presiones: la influencia latina y la evolución desde las estructuras causativas ya en español. 
(15) Et vidit quod sanctus frater cero se posuit ad dormiendum in lecto. (Actus beati Francisci et sociorum eius, siglo XIII, Cross Database Searchtool, Brepols Publishers)

(16) Cum semel ad locum Minorum cum matre et rege fratre venisset, inmediate iuxta regem se posuit ad sedendum. (Historici Germaniae, siglo xII, Cross Database Searchtool, Brepols Publishers)

\subsubsection{La construcción incoativa}

Los ejemplos inequívocamente incoativos se documentan desde finales del siglo XIV. En estos enunciados la construcción incoativa aún está próxima a la etimológica. Así, el infinitivo es siempre un verbo de implica una actividad controlada por el agente, como los verbos que implican desplazamiento; por ejemplo, caminar (17) o ir (18).

(17) \& de continent se puso a caminar aquexadament enta la Suria con hombres de cauallo. (Juan Fernández de Heredia, Traducción de Vidas paralelas de Plutarco, II, 1379-1384, CORDE)

(18) Agissilao se puso a yr en ayuda d'ellos. (Juan Fernández de Heredia, Traducción de Vidas paralelas de Plutarco, II, 1379-1384, CORDE)

Desde principios del siglo XVI se documentan ejemplos en los que ponerse ya no solamente se combina con verbos que implican desplazamiento, sino que también aparecen auxiliados como maldecir (19).

(19) Quando yo me puse a mal dezjr el amor de aquella que yo tanto amo. (Anónimo, Cuento de Tristán de Leonís, 1501- 1533, GradiA)

La presencia de nuevas piezas léxicas en la posición de verbo auxiliado se puede explicar, siguiendo a Comer y Enghels (2018), por medio de un proceso metafórico que se puede condensar en el siguiente esquema: CONCRETO > ABSTRACTO. En este proceso, se pasa de expresar una situación concreta y física (caminar, ir) a una perteneciente a un plano más abstracto y mental, como maldecir.

Siguiendo a Hilpert (2012), se puede afirmar que la presencia de nuevos tipos de verbo en la posición de auxiliado es una consecuencia habitual de cambios semánticos como los que ha experimentado la perífrasis. Estas nuevas clases verbales con las que empieza a combinarse la construcción en el siglo XVI son verbos de percepción, como escuchar (20), de cognición, como pensar (21) o de comunicación, como escribir (22). De todos modos, en todas estas clases verbales el sujeto sigue ejerciendo el control de la 
acción, de modo que la perífrasis todavía mantiene la restricción selectiva heredada del verbo poner.

(20) Si te pones a escuchar lo que te dirán ánimas semejantes nunca acabaremos. (Alfonso de Valdés, Diálogo de Mercurio y Carón, siglo XVI, Gradia)

(21) La otra puerta por donde soy entrado en esta opinión es la consideración de los vocablos castellanos, porque, cuando me pongo a pensar en ellos, hallo que muchos de los que no son latinos o arábigos, son griegos. (Juan de Valdés, Diálogo de la lengua, 1535, Gradia)

(22) Y si, por tiempo, alguno se maravillare que me puse a escribir semejante materia. (Francisco Delicado, La lozana andaluza, 1528, GrADIA)

No obstante, desde finales del siglo XVIII y a lo largo del siglo xIX, la gramaticalización de la construcción incoativa avanza un paso más. A partir de esta fecha, en la posición de verbo auxiliado ya no solamente aparecen verbos que implican actividades controladas, sino que se documentan verbos que no necesariamente seleccionan un sujeto agentivo. Se trata de los verbos que expresan emociones, como reír o llorar (23). Por consiguiente, el control del sujeto sobre la acción se ve debilitado, de modo que la perífrasis se aleja de la construcción etimológica.

(23) Después la señorita Josefina se abrazó a su padre, y este se puso a llorar soltando lagrimones como balas, y luego la arrullaba en sus brazos como si ella fuera un chiquillo. (Benito Pérez Galdós, Gerona, 1874, CORDE)

Es en este siglo, precisamente, cuando la perífrasis incoativa ve incrementada su frecuencia de uso notablemente (Gráfico 1). Este aumento en el uso podría estar motivado por el cambio formal que experimenta la construcción y por la especialización de la perífrasis incoativa en contextos de inmediatez comunicativa (vid. APARTADO 4.4.).

Este proceso de gramaticalización se consolida en el siglo xx, cuando la perífrasis empieza a combinarse con verbos meteorológicos, los cuales no presentan sujeto semántico (24). Con este tipo de verbos, el control de la acción por parte del agente se pierde por completo.

(24) Anduvimos haciendo estatuas hasta que se puso a llover. (Miguel Delibes, Diario de un emigrante, 1958, CORDE) 


\subsection{LA EMERGENCIA DE UNA NUEVA CONSTRUCCIÓN}

Como hemos señalado en el apartado anterior, la perífrasis incoativa ponerse $a+\mathrm{INF}$ ha experimentado un proceso de gramaticalización, partiendo de la estructura causativa hasta llegar a consolidación de la perífrasis incoativa. En ese momento, ha nacido una nueva construcción gramatical, que se ha forjado a partir de una serie de cambios semánticos y sintácticos. En términos de la Gramática de Construcciones Diacrónica, podemos afirmar que se trata de cambios construccionales que han culminado con la construccionalización definitiva de la perífrasis verbal. El objetivo de este apartado es indicar esos cambios formales y de significado que han llevado hasta la nueva construcción gramatical.

\subsubsection{Reestructuración de los constituyentes}

El primer gran cambio que experimenta la construcción respecto a la estructura causativa es la reestructuración de sus constituyentes, la cual conlleva la modificación de la estructura sintáctica y semántica de la perífrasis verbal. El verbo poner, en las construcciones causativas, desempeña la función de núcleo del predicado, es el verbo principal de la oración. Además, subcategoriza siempre un sujeto agentivo (Juan), un objeto directo, que puede ser animado (25) o inanimado (26), y un complemento preposicional introducido por la preposición $a$ seguida de un verbo en infinitivo.

(25) Juan puso a su hijo a trabajar en la empresa familiar.

(26) Juan puso las patatas a cocer en la olla.

En cambio, en la estructura de la perífrasis incoativa, poner ya no aparece como el verbo principal de la oración, sino que funciona como el auxiliar de la perífrasis, y ya no se encarga de la selección de los argumentos en solitario, sino que esa responsabilidad está compartida con el verbo auxiliado, esto es, que depende del conjunto de la construcción. En efecto, ese complemento preposicional de las estructuras causativas ya no es un argumento del verbo principal, sino que se ha convertido en un constituyente más de la perífrasis verbal (la preposición, en el nexo, y el infinitivo, en el verbo auxiliado), el cual desempeña también la función de núcleo del predicado.

Por lo tanto, estas diferencias ponen de manifiesto la emergencia de una nueva construcción gramatical, con su propio funcionamiento sintáctico y con su propio esquema de subcategorización. Esto, además, se refleja en la capacidad combinatoria de ambas construcciones: la construcción causativa mantiene en mayor medida las restricciones heredadas de poner como verbo pleno, puesto que en esas estructuras funciona como un verbo 
principal, no gramaticalizado; en cambio, la perífrasis verbal se encuentra más lejana a esas restricciones, dado que el verbo poner ya no funciona como un verbo pleno, sino que está sometido a la gramaticalización que afecta a toda la construcción gramatical. Por esa razón, en los primeros ejemplos de la perífrasis verbal se mantienen aún las restricciones del verbo poner, mientras que en sus últimos estadios evolutivos ya se ha despojado de dichas restricciones. Por ejemplo, el tipo de sujeto; en las estructuras causativas el sujeto solamente puede funcionar como el agente de la acción, del mismo modo que en los usos léxicos del verbo poner; sin embargo, cuando actúa como auxiliar perifrástico, poner puede presentar sujetos que no ejerzan el control de la acción (27).

(27) Micaela que había oído la conversación, había estado llorando, pero con lo último que dijo Álvaro, se puso a reír, al grado que hasta en la sala se oyó. (Alberto Orellana Ramírez, Por el costado humano, 2005, CORPES XXI)

\subsubsection{El nacimiento del sentido incoativo}

Como señalábamos en el APARTADO 4.2., el significado incoativo que adquiere la perífrasis ponerse $a+$ INF es el resultado del cambio semántico de naturaleza metonímica que experimenta la estructura causativa. En efecto, la construcción no modifica únicamente su estructura sintáctica, sino que adopta un nuevo valor semántico: la incoatividad. En este punto, por lo tanto, ya se han producido dos cambios construccionales, semántico y sintáctico, que dan lugar a una nueva construcción gramatical, todavía incipiente.

\subsubsection{Las clases de verbo auxiliado}

Siguiendo a Hilpert (2012), podemos afirmar que una consecuencia habitual de este tipo de cambios semánticos es la presencia de nuevas clases verbales en la posición de verbo auxiliado. Por lo tanto, ponerse $a+$ INF experimenta un nuevo cambio construccional de tipo sintáctico. Para detallar su desarrollo, vamos a mostrar los tipos de verbos que han ido ocupando la posición de verbo auxiliado de la perífrasis a lo largo del tiempo.

Como hemos mostrado en el APARTADO 4.2., los primeros casos de la perífrasis incoativa se documentan en el siglo XIV. En ese momento, en la posición de verbo auxiliado aparecen verbos de desplazamiento, lo cual, probablemente, se deba a la afinidad semántica que existe con el auxiliar, puesto que poner es un verbo que también implica un desplazamiento. A partir de los siglos XV y XVI, como consecuencia del cambio semántico experimentado por la construcción, comienzan a documentase nuevas 
clases verbales, cuya acción se sitúa en un plano más abstracto (verbos de cognición, de comunicación, de percepción y de actividades), como se ilustra en la Tabla 2. Esto demuestra que el proceso de gramaticalización de la perífrasis continúa avanzando, ya que se ha extendido el contexto de la estructura a un plano más abstracto. En este punto, cabe aclarar que para clasificar los infinitivos que aparecen en nuestro corpus hemos consultado el banco de datos de verbos y construcciones verbales del español ADESSE, en el que se ofrece una caracterización sintáctico-semántica de más de 4000 entradas verbales.

El mayor cambio se produce a finales del siglo XVIII y a lo largo del XIX, cuando se introducen los verbos que expresan emociones, los cuales denotan eventos no controlados por el agente. Esta tendencia se consolida en el siglo $\mathrm{xx}$, cuando se empiezan a documentar verbos meteorológicos como auxiliados perifrásticos, los cuales ya no presentan sujeto semántico. Por lo tanto, en este punto, se consolida este cambio construccional que contribuye a la construccionalización definitiva de la perífrasis verbal.

\begin{tabular}{|c|c|c|c|c|c|c|}
\hline Clase verbal & XV & XVI & XVII & XVIII & XIX & $\mathbf{X X}$ \\
\hline Desplazamiento & $\begin{array}{l}50 \% \\
(1 / 2)\end{array}$ & $\begin{array}{l}18,8 \% \\
(3 / 16)\end{array}$ & - & - & $\begin{array}{c}12 \% \\
(9 / 75)\end{array}$ & $\begin{array}{l}9,8 \% \\
(9 / 92)\end{array}$ \\
\hline Cognición & $\begin{array}{l}50 \% \\
(1 / 2)\end{array}$ & $\begin{array}{l}18,8 \% \\
(3 / 16)\end{array}$ & - & $\begin{array}{l}8,3 \% \\
(1 / 12)\end{array}$ & $\begin{array}{r}14,7 \% \\
(11 / 75)\end{array}$ & $\begin{array}{c}12 \% \\
(11 / 92)\end{array}$ \\
\hline Comunicación & - & $\begin{array}{l}31,3 \% \\
(5 / 16)\end{array}$ & $\begin{array}{c}100 \% \\
(1 / 1)\end{array}$ & $\begin{array}{c}50 \% \\
(6 / 12)\end{array}$ & $\begin{array}{c}28 \% \\
(21 / 75)\end{array}$ & $\begin{array}{c}14,1 \% \\
(13 / 92)\end{array}$ \\
\hline Percepción & - & $\begin{array}{l}6,1 \% \\
(1 / 16)\end{array}$ & - & - & $\begin{array}{l}5,3 \% \\
(4 / 75)\end{array}$ & $\begin{array}{l}2,2 \% \\
(2 / 92)\end{array}$ \\
\hline Actividad & - & $\begin{array}{c}25 \% \\
(4 / 16)\end{array}$ & - & $\begin{array}{l}33,4 \% \\
(4 / 12)\end{array}$ & $\begin{array}{c}24 \% \\
(18 / 75)\end{array}$ & $\begin{array}{l}29,3 \% \\
(27 / 92)\end{array}$ \\
\hline Emociones & - & - & - & $\begin{array}{l}8,3 \% \\
(1 / 12)\end{array}$ & $\begin{array}{c}16 \% \\
(12 / 75)\end{array}$ & $\begin{array}{l}26,1 \% \\
(24 / 92)\end{array}$ \\
\hline Meteorológicos & - & - & - & - & - & $\begin{array}{l}6,5 \% \\
(6 / 92)\end{array}$ \\
\hline
\end{tabular}

Tabla 2. Distribución de tiempos y modos verbales en ponerse $a+$ INF por siglo

Por último, en la Tabla 2 puede observarse que las clases verbales más recurrentes son los verbos de comunicación, los de actividades y los que expresan emociones. Esto se debe, probablemente, a que se trata de una 
construcción muy frecuente en los textos narrativos (vid. APARTADO 4.4.), ya que en las narraciones es habitual la expresión de los sentimientos, la interacción entre los personajes y la descripción de actividades.

\subsubsection{Los tiempos y modos verbales}

Otro cambio en la forma de la perífrasis verbal que permite demostrar la construccionalización que experimenta es su capacidad de conjugarse en los distintos tiempos y modos del sistema verbal. Para ello, vamos a observar la evolución de los tiempos y modos en los que aparece el verbo auxiliar de la perífrasis a lo largo del tiempo.

Desde una perspectiva general, a lo largo de la historia esta perífrasis se conjuga principalmente en presente de indicativo y en pretérito indefinido, como puede observarse en la Tabla 3. Esto es esperable, puesto que es una construcción que se emplea de manera destacable en los textos narrativos (vid. APARTADO 4.4.), donde los tiempos verbales más frecuentes son los mencionados.

Desde un punto de vista diacrónico, se produce una evolución en el tiempo en el que se conjuga la perífrasis. Hasta el siglo XVIII, ponerse a + INF se conjuga solamente en presente de indicativo y en pretérito indefinido; en la misma línea, los ejemplos encontrados en latín aparecen únicamente conjugados en pretérito indefinido. No obstante, a partir de los siglos XIX y $\mathrm{xx}$, se suman el resto de los tiempos verbales que aparecen en la Tabla 3. Esta diversidad puede deberse al avance en el proceso de gramaticalización que experimenta la construcción en ese siglo. En efecto, la posibilidad de una construcción de conjugarse en distintos tiempos y modos es un indicio del avance de su gramaticalización.

\begin{tabular}{|l|c|c|c|}
\hline Tiempo y modo & Ocurrencias & Tiempo y modo & Ocurrencias \\
\hline Pretérito indefinido & $62(31,4 \%)$ & P. plusc. de indicativo & $5(2,5 \%)$ \\
\hline Presente de indicativo & $58(29,4 \%)$ & Gerundio & $4(2 \%)$ \\
\hline Infinitivo & $27(13,6 \%)$ & Imperativo & $4(2 \%)$ \\
\hline P. imperfecto de ind. & $19(9,6 \%)$ & P. perfecto de indicativo & $3(1,5 \%)$ \\
\hline P. imperfecto de sub. & $8(4 \%)$ & Futuro simple & $2(1 \%)$ \\
\hline Presente de subjuntivo & $5(2,5 \%)$ & Condicional simple & $1(0,5 \%)$ \\
\hline
\end{tabular}

Tabla 3. Distribución de tiempos y modos verbales en ponerse $a+$ INF 


\subsubsection{El tipo de sujeto}

Otro cambio que experimenta la construcción perifrástica y que contribuye a su construccionalización definitiva es la pérdida del control de la acción por parte del sujeto. Como puede observarse en la Tabla 4, desde sus inicios, la perífrasis ponerse $a+$ INF subcategoriza sujetos animados que controlan la acción expresada por el verbo auxiliado (28). Como hemos señalado en el APARTADO 3, este rasgo es heredado de los usos léxicos del verbo poner, el cual selecciona siempre sujetos agentivos, animados y volitivos. No obstante, a partir del siglo XIX, empiezan a documentarse ejemplos donde se percibe un debilitamiento del control de la acción por parte del sujeto, puesto que, pese a ser animados, se trata de sujetos no agentivos ni volitivos (29). Por lo tanto, en este punto, la construcción perifrástica va dejando atrás las características heredadas de los usos plenos del verbo auxiliar. Esta tendencia se consolida en el siglo xx, cuando aparecen también sujetos impersonales, de modo que el sujeto deja de ejercer cualquier tipo de control sobre el evento (30). Este cambio hacia los sujetos sin control puede haber sido propiciado por la deriva hacia la tercera persona que experimenta la construcción a partir del siglo XIX.

(28) Habrá una hora que acabé de trasladar un sermón, y, cansado ya de escribir, me puse a leer en un libro el más guapo que he leído, ni pienso leer en todos los días de mi vida. (José Francisco de Isla, Fray Gerundio de Campazas, 1758, Gradia)

(29) Un día, impensadamente, se puso a llorar. Lloraba de una manera extraña, cortada y rápida, con ganas de acabar pronto. (Carmen Laforet, Nada, 1945, GradiA)

(30) Alicia se vino conmigo para abajo y por el camino no hablamos casi nada. Se había puesto a llover. (Carmen Martín Gaite, Entre visillos, 1958, CORDE)

\begin{tabular}{|l|c|c|c|c|c|c|}
\hline Tipo de sujeto & XV & XVI & XVII & XVIII & XIX & XX \\
\hline Animado (+ control) & $\begin{array}{c}100 \% \\
(2 / 2)\end{array}$ & $\begin{array}{c}100 \% \\
(16 / 16)\end{array}$ & $\begin{array}{c}100 \% \\
(1 / 1)\end{array}$ & $\begin{array}{c}91,7 \% \\
(11 / 12)\end{array}$ & $\begin{array}{c}84 \% \\
(63 / 75)\end{array}$ & $\begin{array}{c}67,4 \% \\
(62 / 92)\end{array}$ \\
\hline Animado (- control) & - & - & - & $\begin{array}{c}8,3 \% \\
(1 / 12)\end{array}$ & $\begin{array}{c}16 \% \\
(12 / 75)\end{array}$ & $\begin{array}{c}26,1 \% \\
(24 / 92)\end{array}$ \\
\hline Impersonal & - & - & - & - & - & $\begin{array}{c}6,5 \% \\
(6 / 92)\end{array}$ \\
\hline
\end{tabular}

Tabla 4. Distribución del tipo de sujeto en ponerse a + INF por siglo 


\subsubsection{La elevación de clíticos}

Un criterio empleado para demostrar la gramaticalización de una perífrasis verbal es su capacidad de anteposición de los pronombres clíticos. En el caso de ponerse $a+$ INF, este cambio se produce en el siglo XVII, cuando la construcción admite los primeros casos de elevación de pronombres clíticos (31), ya que en siglos anteriores no se documentan ejemplos. De todos modos, a partir de ese momento, no se percibe una evolución en ese aspecto, puesto que se siguen dando casos de anteposición de clíticos hasta la actualidad (32), pese a no ser un fenómeno muy frecuente.

(31) Hablaua con mucha sinceridad y llaneza con su Señor y sin aduertir si la ohian o no, y assi se la ponían a escuchar algunas, porque se edificauan mucho de verla puesta en estas razones con Dios. (Fray José Sigüenza, Tercera parte de la Historia de la orden de San Jerónimo, 1605, CORDE)

(32) Tomás coge una revista y se la pone a leer. (Cesc Gay; Tomás Aragay, Truman, 2016, CORPES XXI)

\subsection{TRADICIONES DISCURSIVAS}

Como puede observarse en la Tabla 5, ponerse $a+$ INF alcanza sus porcentajes de empleo más elevados en el texto narrativo. Si a esto le añadimos que para la época contemporánea las mayores frecuencias de uso se concentran en los textos orales, se puede concluir que estamos ante una perífrasis que ha ido especializándose en contextos de proximidad comunicativa, en términos de Koch y Oesterreicher (2007).

\begin{tabular}{|l|c|c|c|c|c|c|}
\hline Tradición disc. & XV & XVI & XVII & XVIII & XIX & XX \\
\hline Narrativa & $100 \%$ & $6,2 \%$ & $100 \%$ & $58,3 \%$ & $90,7 \%$ & $35,9 \%$ \\
& $(2 / 2)$ & $(1 / 16)$ & $(1 / 1)$ & $(7 / 12)$ & $(68 / 75)$ & $(33 / 92)$ \\
\hline \multirow{2}{*}{ Epistolar } & - & $\begin{array}{c}25 \% \\
(4 / 16)\end{array}$ & - & $\begin{array}{c}16,7 \% \\
(2 / 12)\end{array}$ & $\begin{array}{c}4 \% \\
(3 / 75)\end{array}$ & - \\
\hline \multirow{2}{*}{ Diálogos } & - & $\begin{array}{c}68,8 \% \\
(11 / 16)\end{array}$ & - & - & - & - \\
\hline \multirow{2}{*}{ Ensayos } & - & - & - & $\begin{array}{c}25 \% \\
(3 / 12)\end{array}$ & - & - \\
\hline
\end{tabular}




\begin{tabular}{|l|c|c|c|c|c|c|}
\hline Prensa & - & - & - & - & $\begin{array}{c}5,3 \% \\
(4 / 75)\end{array}$ & - \\
\hline Oral & - & - & - & - & - & $\begin{array}{c}64,1 \% \\
(59 / 92)\end{array}$ \\
\hline
\end{tabular}

Tabla 5. Frecuencia de ponerse $a+$ INF según el tipo de texto

Para acabar de corroborar esta tendencia, se ha realizado una búsqueda complementaria en CORDE para observar en qué tipo de textos suele aparecer la construcción. Hasta el siglo XVIII, ponerse $a+$ INF aparece tanto en textos de proximidad comunicativa, como la narrativa (33), como en tipologías propias de la distancia comunicativa, como la historiografía (34).

(33) Bridway vuelve con tintero, pluma y papel, y Eusebio se pone a escribir. (Pedro Montengón, Eusebio, 1786, CORDE)

(34) El cronista Herrera, aunque tan juicioso y moderado, cuando se pone a hacer la comparación del cielo y tierra de Europa con los de América, se muestra ignorante aun de los elementos de la geografía. (Francisco Javier Clavijero, Historia Antigua de México, 1780, CoRDE)

No obstante, a partir del siglo XIX, no se encuentran ejemplos de ponerse $a+\mathrm{INF}$ en tipologías textuales propias de la distancia comunicativa. Por lo tanto, parece que se produjo una especialización de esta construcción en tradiciones discursivas de proximidad comunicativa. Esto pudo propiciar el aumento de la frecuencia de empleo de ponerse $a+$ INF en el siglo XIX, puesto que se trata de una perífrasis que consolida su empleo en contextos de inmediatez comunicativa.

\section{CONCLUSIONES}

Tras el análisis diacrónico, podemos concluir que ponerse $a+$ INF es una construcción incoativa que tiene su origen en estructuras causativas formadas por el verbo poner y un sintagma preposicional constituido por la preposición $a$ y un infinitivo. Este tipo de construcciones presenta dos interpretaciones: la causativa, en la que el verbo poner mantiene su valor locativo, y una acepción cercana a la incoativa, en la que se infiere que el hecho de colocar algo en un lugar determinado es el detonante para que se inicie la acción expresada por el infinitivo. Por lo tanto, en estas estructuras se encuentra el germen de la perífrasis incoativa, que empieza a documentarse a finales del 
siglo XIV y a principios del XV. En esos siglos se produjo el primer cambio construccional, de tipo semántico, a partir del cual se llegó al significado incoativo que presentan estas construcciones en la actualidad. El motor del cambio fue una metonimia consistente en una asociación por contigüidad, en la que se pasó de la noción de colocar algo en un lugar para realizar una acción > comenzar a realizar dicha acción.

Este cambio semántico propició la emergencia de un cambio sintáctico que se fue fraguando entre los siglos XVI y Xx. Este cambio consistía en la presencia de nuevas piezas léxicas en la posición de verbo auxiliado. En los primeros ejemplos perifrásticos los auxiliados eran verbos de movimiento, pero entre los siglos XVI y XVIII comienzan a aparecer clases verbales que denotan actividades más abstractas (verbos de comunicación, de actividad mental y de percepción). Ahora bien, todos ellos eran verbos que expresan actividades controladas por el sujeto. Sin embargo, en el siglo XIX empiezan a documentarse casos en los que se produce un debilitamiento en el control de la acción, como los verbos de emociones (reír y llorar), cuyo sujeto no es el agente de la acción. Esta pérdida en el control de la acción se reafirma en el siglo xx, cuando los auxiliados comienzan a ser verbos de sujeto cero. Por lo tanto, en este punto se consolida la gramaticalización de ponerse a + INF y tiene lugar la construccionalización de la perífrasis, la cual ya se ha alejado de las restricciones de poner como verbo pleno.

Esta construccionalización ha sido el resultado de una serie de cambios construccionales, semánticos y sintácticos, que han ido teniendo lugar a lo largo de la evolución de la construcción: la reestructuración de los constituyentes perifrásticos, la adquisición del valor incoativo, el pronombre personal del auxiliar perifrástico, la presencia de nuevas clases verbales en la posición de verbo auxiliado, el debilitamiento del control de la acción por parte del sujeto, la capacidad de conjugarse en los distintos tiempos y modos del paradigma verbal, y la posibilidad de elevación de clíticos.

En cuanto a los rasgos semánticos y sintácticos que presenta la perífrasis en la actualidad, podemos afirmar que ponerse $a+$ INF es una perífrasis aspectual incoativa, puesto que indica el inicio de la acción expresada por el infinitivo. No obstante, a diferencia de otras perífrasis de significación análoga, como comenzar $a+\mathrm{INF}$ y empezar $a+\mathrm{INF}$, presenta una mayor intensidad y brusquedad a la hora de expresar el comienzo de la acción.

Asimismo, ponerse $a+$ INF manifiesta otros rasgos diferenciales respecto a las mencionadas perífrasis incoativas, como su limitada productividad. Como se ha podido observar, se trata de una perífrasis que solamente aparece, aunque de manera relevante, en contextos de proximidad comunicativa, por lo que no tiene cabida en ámbitos de mayor formalidad, como sí ocurre con comenzar $a+\mathrm{INF}$ y empezar $a+\mathrm{INF}$. Además, en contraposición a estas 
dos perífrasis incoativas, ponerse $a+$ INF presenta limitaciones relativas al aspecto léxico, puesto que solo se combina con verbos que expresen acciones durativas, las cuales, además, deben poder segmentarse en fases. Esto ocurre porque ponerse $a+$ INF se focaliza en un punto del evento, de ahí que no pueda combinarse con verbos cuya acción expresada implique cierta gradualidad, como amanecer, envejecer o adelgazar. Por consiguiente, se trata de una construcción que presenta una serie de restricciones que impiden que se considere una perífrasis verbal prototípica. Sin embargo, dado que supera positivamente la mayoría de los criterios establecidos por la gramática tradicional para la identificación de construcciones perifrásticas, se puede considerar una perífrasis verbal no prototípica, situada en los márgenes de la categoría.

\section{REFERENCIAS BIBLIOGRÁFICAS}

\subsection{Fuentes DOCUMENTALES}

CDL: Cross Database Searchtool. Brepolis Library of Latin Texts Series A-B, Turnhout, Grepols. Consultado en: http://www.brepolis.net [2019].

CORDE: Corpus diacrónico del español. Banco de datos de la Real Academia Española. Consultado en http://corpus.rae.es/cordenet.html [2018-2019].

CORPES XXI: Corpus del Español del Siglo XXI. Banco de datos de la Real Academia Española. Consultado en http://corpus.rae.es/cordenet.html [2018-2019].

Gradia: Corpus GRaDIA. Cuerpo de texto del grupo de investigación Gramática y Diacronía (UB). Consultado en: http://Gradiadiacronia.wixsite.com/Gradia/ corpus-Gradia [20182019].

\subsection{REFERENCIAS BIBLIOGRÁFICAS}

ADESSE. 2019. Base de datos de verbos, alternancias de diátesis y esquemas sintácticosemánticos del español (Universidad de Vigo). Consultado en: http://webs.uvigo.es/ adesse/.

BarĐdal, Jóhanna y Spike Gildea. 2015. Diachronic Construction Grammar: Epistemological context, basic assumptions and historical implications. En Barðdal, J., E. Smirnova, L. Sommerer, S. Gildea, (eds.). Diachronic Construction Grammar, pp. 1-50. Amsterdam: John Benjamins.

Comer, Marie y Renata Enghels. 2018. Evaluating grammaticalization and constructional accounts: The development of the inchoative construction with put verbs in Spanish. En Coussé, E., P. Andersson, J. Olofsson (eds.). Grammaticalization meets Construction Grammar, pp. 107-133. Amsterdam: John Benjamins.

Fernández de CAstro, Félix. 1990. Las perífrasis verbales en español: comportamiento sintáctico e historia de su caracterización. Oviedo: Publicaciones del Departamento de Filología Española. 1999. Las perífrasis verbales en el español actual. Madrid: Gredos. 
FERNÁNDEZ-ORdóÑEZ, InÉs. 2006. La Historiografía medieval como fuente de datos lingüísticos. Tradiciones consolidadas y rupturas necesarias. En J. L. Girón Alconchel. J. J. de Bustos, (eds.). Actas del VI Congreso Internacional de Historia de la Lengua Española, vol. II, pp. 1779-1807. Madrid: Arco/Libros.

Fogsgaard, Lene. 2002. Algunas perifrasis aspectuales del español. San Vicente del Raspeig: Publicaciones de la Universidad de Alicante.

Garachana Camarero, Mar (ed.). 2017. La gramática en la diacronía. La evolución de las perifrasis verbales modales en español. Madrid/Frankfurt: Iberoamericana/Vervuert.

García Fernández, Luis (dir.) et al. 2006. Diccionario de perífrasis verbales. Madrid: Gredos.

Gómez Torrego, Leonardo. 1988. Perífrasis verbales: sintaxis, semántica y estilística. Madrid: Arco/Libros.

1999. Los verbos auxiliares. Las perífrasis verbales de infinitivo. En I. Bosque, V. Demonte (eds.). Gramática descriptiva de la lengua española, pp. 3323-3390. Madrid: Espasa-Calpe.

HilPERT, MARTIN. 2012. Diachronic collostructional analysis meets the noun phrase: Studying many a noun in COHA. En T. Nevalainen, E. Closs Traugott (eds.). The Oxford Handbook of the History of English, pp. 233-244. Oxford: Oxford University Press.

Koch, Peter y Wulf Oesterreicher. 2007. Lengua hablada en la Romania: español, francés, italiano. Madrid: Gredos.

Morera, Marcial. 1991. Diccionario crítico de las perífrasis verbales del español. Puerto del Rosario: Servicio de Publicaciones del Cabildo Insular de Fuerteventura.

Olbertz, Hella. 1998. Verbal periphrases in a functional grammar of Spanish. Berlin/New York: Walter de Gruyter.

Real Academia Española. Diccionario de la lengua española (23a ed.). [en línea]. Consultado en http://www.rae.es/rae.html [2018-2019].

Real Academia Española. Diccionario panhispánico de dudas. (DPD). [en línea]. Consultado en http://www.rae.es/recursos/diccionarios/dpd [2018-2019].

Rae y Asale. 2009. Nueva Gramática de la Lengua Española. Madrid: Espasa.

Roca Pons, José. 1958. Estudios sobre perifrasis verbales del español. Madrid: Anejo LXVII de la Revista de Filología Española.

RODRÍGUEZ MOLINA, JAVIER. 2010. La gramaticalización de los tiempos compuestos en español antiguo: Cinco cambios diacrónicos. Madrid: Universidad Autónoma de Madrid.

Rodríguez Molina, Javier y Álvaro S. Octavio de Toledo y Huerta. 2017. La imprescindible distinción entre texto y testimonio: el CORDE y los criterios de fiabilidad lingüística. Scriptum Digital, 6: 5-68.

Traugott, Elizabeth Closs y Graeme Trousdale. 2013. Constructionalization and Constructional Changes. Oxford: Oxford University Press.

Yllera, Alicia. 1980. Sintaxis histórica del verbo español: las perifrasis verbales. Zaragoza: Universidad de Zaragoza.

1999. Las perífrasis verbales de gerundio y participio. En Ignacio Bosque y Violeta Demonte (eds.). Gramática Descriptiva de la Lengua Española, pp. 3391-3442. Madrid: Espasa Calpe. 